\title{
Produtividade do algodoeiro herbáceo em plantio direto no Cerrado com rotação de culturas
}

\author{
José Carlos Corrêa ${ }^{(1)}$ e Ravi Datt Sharma ${ }^{(1)}$ \\ (1)Embrapa Cerrados, Caixa Postal 08223, CEP 73301-970 Planaltina, DF. E-mail: correa@cpac.embrapa.br, sharma@cpac.embrapa.br
}

\begin{abstract}
Resumo - O experimento, instalado em um Latossolo Vermelho-Amarelo muito argiloso, teve o objetivo de avaliar o efeito da rotação de culturas na produtividade do algodoeiro herbáceo (Gossypium hirsutum L. r. latifolium Hutch) em plantio direto sob condições de sequeiro no Cerrado. O delineamento experimental foi de blocos casualizados com cinco tratamentos e quatro repetições. Os tratamentos consistiram das rotações sojamilheto-soja-milheto-algodoeiro; soja-amaranto-soja-nabo forrageiro-soja-algodoeiro; soja-sorgo granífero-sojasorgo granífero-algodoeiro; soja-aveia preta-soja-aveia preta-algodoeiro e soja-soja-algodoeiro. A maior produtividade do algodoeiro foi obtida com a rotação de soja e milheto, em que houve melhor controle de plantas daninhas.
\end{abstract}

Termos para indexação: Gossypium hirsutum, planta daninha, planta de cobertura.

\section{Herbaceous cotton yield in no-till system in rainfed Savannah conditions with crop rotation}

\begin{abstract}
The experiment was carried out in a heavy red yellow latosol and aimed at evaluating crop rotation on herbaceous cotton yields in no-till system under rainfed Savannah conditions. The experimental design used was a completely randomised blocks with five treatments: soybean-millet-soybean-millet-cotton; soybeanamaranth-soybean-forage radish-soybean-cotton; soybean-grain sorghum-soybean-grain sorghum-cotton; soybean-black rye-soybean-black rye-cotton and soybean-soybean-cotton and four replications. The highest cotton seed yield was obtained in the sequence soybean-millet-soybean-millet-cotton, in which best weed control also occurred.
\end{abstract}

Index terms: Gossypium hirsutum, weeds, cover plants.

\section{Introdução}

O cultivo do algodoeiro herbáceo tem sido uma opção para integrar o sistema produtivo no Cerrado. Apesar de a fertilidade natural dos solos ser muito baixa, exigindo grandes investimentos em correção e fertilização, a topografia favorece a mecanização das áreas de plantio e permite bom desenvolvimento do algodoeiro e obtenção de fibra de alta qualidade (Takizawa \& Guerra, 1998).

Entre os diversos fatores que afetam o crescimento, desenvolvimento e produtividade desta malvácea, destacam-se os sistemas de manejo do solo. Implementos de discos (arado e grade) usados no preparo das áreas para plantio e o monocultivo contribuem para a degradação dos solos. Alguns autores (Lagiére, 1976; GridPapp et al., 1992) enfatizam que um bom preparo do solo é fundamental para a germinação e desenvolvimento homogêneo da cultura, e facilita o cultivo e a colheita do algodoeiro. Melo Filho \& Silva (1993) sugerem a adoção de sistemas de preparo do solo que reduzam as perdas de terra e proporcionem maior aproveitamento da água. Segundo Anderson (1983), quando são aplicadas as mesmas práticas culturais seguidamente ano após ano, no mesmo solo, a associação de plantas daninhas tende a ampliar-se, refletindo negativamente na produção, na qualidade dos produtos e nos lucros. Conforme Derpsch (1985), a rotação pode controlar a erosão, conservar a umidade do solo, reduzir o dispêndio de fertilizantes e agrotóxicos e ampliar os períodos de utilização de máquinas e implementos.

Yamaoka (1991) mostrou que a produção do algodoeiro em plantio direto foi superior ao plantio convencional. Em pesquisas de longa duração, Brown et al. (1995) e Smart \& Bradford (1998) observaram que a produção e a qualidade da fibra do algodão obtidas no plantio direto fo- 
ram iguais as do sistema convencional. A principal vantagem do plantio direto foi o controle da erosão.

O objetivo deste trabalho foi avaliar o efeito da rotação de culturas na produtividade do algodoeiro herbáceo em plantio direto, sob condições de sequeiro no Cerrado.

\section{Material e Métodos}

O experimento foi instalado em setembro de 1998 em um Latossolo Vermelho-Amarelo muito argiloso (64\% de argila, $14 \%$ de silte, $18 \%$ de areia fina e $4 \%$ de areia grossa), localizado no campo experimental da Embrapa Cerrados. Aplicou-se calcário dolomítico para elevar a saturação de bases para 60\%; metade do calcário foi incorporada por meio de gradagem (grade aradora) e aração (arado de discos), até a profundidade de $30 \mathrm{~cm}$; outra metade foi incorporada com grade niveladora.

O delineamento experimental foi de blocos casualizados com cinco tratamentos e quatro repetições. As parcelas tiveram as dimensões de 8,0x15,0 m $\left(120 \mathrm{~m}^{2}\right)$. Os tratamentos consistiram de cultivos sucessivos de soja-milheto-soja-milheto-algodoeiro (T1); sojaamaranto-soja-nabo forrageiro-soja-algodoeiro (T2); soja-sorgo granífero-soja-sorgo granífero-algodoeiro (T3); soja-aveia preta-soja-aveia preta-algodoeiro (T4) e soja-soja-algodoeiro (T5).

Em novembro de 1998, foi realizado o plantio convencional da soja (cultivar Conquista) em todas as parcelas. Após a colheita da soja em abril de 1999, foi realizado o plantio direto do milheto (Pennisetum glaucum R. Br.) variedade BN2, amaranto (Amaranthus hipocondriacus Rob.), sorgo granífero (Sorghum vulgare perse) variedade BRS 306, aveia preta (Avena strirgosa Schreb) e, em novembro, o plantio direto da soja (cultivar EMGOPA 316) sobre a palhada dessas plantas.

Após a colheita da soja em abril de 2000, foram realizados os plantios direto do milheto (T1), do nabo forrageiro (Raphanus sativus L.) que substituiu o amaranto em virtude de problemas na germinação (T2), do sorgo granífero (T3) e da aveia preta (T4) e, em novembro, o plantio direto do algodoeiro (cultivar BRS Antares), em todas as parcelas, sobre a palhada das plantas de cobertura.

Os espaçamentos, para os plantios da soja e do algodoeiro, foram de $0,40 \mathrm{~m}$ entre linhas, com 25 plantas por metro, e 0,80 m com 10 a 12 plantas por metro, respec- tivamente. Foi feita adubação de manutenção nos plantios da soja, $400 \mathrm{~kg} / \mathrm{ha}$ da mistura 0:15:35, e do algodoeiro, $750 \mathrm{~kg} / \mathrm{ha}$ da mistura 4:14:8, e aplicação de $60 \mathrm{~kg} / \mathrm{ha}$ de $\mathrm{N}$ em cobertura, 35 dias após o plantio. Para o controle das plantas daninhas e dessecação das plantas de cobertura, em todos os tratamentos, foi aplicada mistura de herbicidas: $2 \mathrm{~L}$ de glyphosate, $480 \mathrm{~g}$ do sal de isopropilamina, e $1 \mathrm{~L}$ de $2,4 \mathrm{D}, 806 \mathrm{~g} / \mathrm{L}$ do sal dimetilamina do ácido 2,4 diclorofenoxiacético. Os tratamentos fitossanitários foram feitos de acordo com as recomendações para cada cultura. Foram avaliados a produtividade do algodoeiro, a altura de plantas, número de capulhos/planta, peso de capulho e porcentagem de sementes e fibras.

O levantamento de plantas daninhas, realizado aos 80 dias após o plantio do algodoeiro, e a coleta da parte aérea da soja das plantas de cobertura e do algodoeiro foram feitos por meio de uma moldura de madeira (um metro quadrado) lançada, ao acaso, três vezes em cada parcela. A parte aérea foi secada em estufa a $65^{\circ} \mathrm{C}$ por 72 horas e pesada. As amostras de solo, coletadas na época da floração do algodoeiro, com trado holandês, foram analisadas para determinar os teores de $\mathrm{Ca}, \mathrm{Mg}$ e $\mathrm{Al}$ (extração com $\mathrm{KCl} 1 \mathrm{~N}$ ), $\mathrm{K}$ e $\mathrm{P}$ (extração com a mistura de $\mathrm{H}_{2} \mathrm{SO}_{4} 0,025 \mathrm{~N}$ e $\mathrm{HCl} \quad 0,05 \mathrm{~N}$ ). O Ca e $\mathrm{Mg}$ foram determinados por espectrometria de absorção atômica; o Al, por titulação; o K, por fotometria de chama e o P, pelo método de Murphy \& Riley (1962). O C orgânico foi determinado segundo método de Walkey \& Black (Allison, 1965).

\section{Resultados e Discussão}

Não foram observadas diferenças significativas entre as produtividades da soja no primeiro ano com preparo convencional (1998/1999) e no segundo ano (1999/2000) com plantio direto (Tabela 1). As maiores produtividades do algodoeiro (algodão em caroço), em plantio direto, foram obtidas nos tratamentos com as rotações soja-milheto (T1), soja-sorgo (T3) e soja-aveia (T4) e as menores, nos tratamentos soja-nabo forrageiro (T2) e soja-soja (T5). Em nove ensaios realizados no Cerrado, conforme Freire \& Farias (1998), a produtividade média do algodoeiro cultivar BRS Antares variou de $4.565 \mathrm{~kg} / \mathrm{ha}$ a $1.609 \mathrm{~kg} / \mathrm{ha}$, de acordo com o manejo da cultura.

Não houve diferença significativa entre os tratamentos quanto ao número de capulhos/planta e peso médio de um capulho (Tabela 2). Em experimentos realizados no Estado do Mato Grosso do Sul, a altura e o peso de 
capulho/planta da cultivar BRS Antares foram, respectivamente, 1,61 m e 5,06 g no Município de Servíria (Bolonhezi et al., 1999) e 1,22 m e 5,55 g no Município de Dourados (Fortuna et al., 1999).

Nos anos agrícola 1998/1999 e 1999/2000, não houve diferença entre as produções de parte aérea da soja (Tabela 3). As produções de parte aérea das plantas de cobertura foram relativamente baixas por causa da distribuição irregular e ausência de chuva nos períodos de desenvolvimento. No tratamento T2, o amaranto plantado em março de 1999, após a colheita da soja, não germinou por falta de umidade na camada superficial do solo, e o nabo forrageiro, que substituiu o amaranto no ano 2000, foi severamente atacado por pulgão (Aphis gossypii Glover). Segundo Bernoit (1977), há dois períodos críticos no ciclo de desenvolvimento das plantas quanto à água disponível. O primeiro ocorre imediata-

Tabela 1. Efeito da rotação de cultivos na produtividade (t/ha) de grãos da soja (1998/1999 e 1999/2000) e do algodoeiro herbáceo, cultivar BRS Antares (2000/2001) em sistemas de plantio direto no Cerrado $^{(1)}$.

\begin{tabular}{|c|c|c|c|}
\hline \multirow[t]{2}{*}{ Tratamento $^{(2)}$} & \multicolumn{2}{|c|}{ Soja } & \multirow{2}{*}{$\begin{array}{c}\text { Algodão em caroço } \\
2000 / 2001 \\
(\mathrm{PD})\end{array}$} \\
\hline & $\begin{array}{c}1998 / 1999 \\
(\mathrm{PC})\end{array}$ & $\begin{array}{c}1999 / 2000 \\
(\mathrm{PD})\end{array}$ & \\
\hline $\mathrm{T} 1$ & $2,7 \mathrm{a}$ & $3,0 \mathrm{a}$ & $4,7 \mathrm{a}$ \\
\hline $\mathrm{T} 2$ & $2,7 \mathrm{a}$ & $3,0 \mathrm{a}$ & $2,6 b$ \\
\hline T3 & $2,6 \mathrm{a}$ & $3,2 \mathrm{a}$ & $3,6 \mathrm{ab}$ \\
\hline $\mathrm{T} 4$ & $2,8 \mathrm{a}$ & $3,1 \mathrm{a}$ & $3,5 \mathrm{ab}$ \\
\hline T5 & $2,6 a$ & $2,7 \mathrm{a}$ & $2,7 b$ \\
\hline $\mathrm{CV}(\%)$ & 8,82 & 8,88 & 17,47 \\
\hline $\mathrm{F}$ & $0,62 *$ & $1,81^{*}$ & $8,66^{* *}$ \\
\hline
\end{tabular}

${ }^{(1)}$ Médias com a mesma letra na coluna não diferem entre si a $5 \%$ de probabilidade, pelo teste de Tukey; PC: preparo convencional; PD: plantio direto. ${ }^{(2)} \mathrm{T} 1$ : soja-milheto-soja-milheto-algodoeiro; T2: soja-amarantosoja-nabo forrageiro-soja-algodoeiro; T3: soja-sorgo granífero-soja-sorgo granífero-algodoeiro; T4: soja-aveia preta-soja-aveia preta-algodoeiro; T5: soja-soja-algodoeiro. mente após o plantio, quando a planta está germinando. Um longo período de seca nessa época pode prejudicar a germinação e tornar necessário o replantio. $\mathrm{O}$ segundo ocorre no florescimento, quando a falta de água pode reduzir a produção. Stewart et al. (1975) observaram um decréscimo significativo na produção do sorgo granífero em todos os tratamentos em que houve déficit acentuado de água.

$\mathrm{O}$ efeito da cobertura morta na emergência das plantas daninhas e, conseqüentemente, na produtividade do algodoeiro, foi significativo. Nos tratamentos T1, T3 e T4, com menor ocorrência de plantas daninhas (Tabela 4), as produtividades do algodoeiro em caroço foram maiores (Tabela 1). O algodoeiro herbáceo, por ser uma planta de crescimento inicial muito lento, é extremamente sensível à competição causada por plantas daninhas (Ashley, 1972). O período crítico de competição entre as plantas daninhas e o algodoeiro herbáceo é dos 15 aos 56 dias (Beltrão \& Melhorança, 1998).

É importante que a cultura permaneça em área limpa nos primeiros 60 dias após a emergência, pois esse período é crítico e os danos são irreversíveis, afetando o número de capulhos por planta e o peso médio de capulhos (Beltrão \& Bezerra, 1993). A cobertura morta, proveniente da rotação de culturas, desempenha importante papel no controle de plantas daninhas, pois muitas sementes de certas espécies de plantas daninhas não germinam quando cobertas por uma camada uniforme de resíduo vegetal. De acordo com Roman \& Velloso (1993), o atraso na germinação de plantas daninhas depende do tipo de resteva vegetal, de sua distribuição e quantidade.

O milheto foi a planta de cobertura que mais produziu parte aérea, atingindo 5 e 6 t/ha, respectivamente, nos anos agrícolas 1999 e 2000 (Tabela 3). É provável que a ação do milheto seja em maior grau por competição, ainda que haja referências do efeito alelopático da pa-

Tabela 2. Componentes de produtividade do algodoeiro herbáceo, cultivar BRS Antares em plantio direto no Cerrado.

\begin{tabular}{cccccc}
\hline Tratamento $^{(1)}$ & $\begin{array}{c}\text { Altura } \\
(\mathrm{cm})\end{array}$ & $\begin{array}{c}\text { Capulhos/plantas } \\
(\text { número) }\end{array}$ & $\begin{array}{c}\text { Peso do capulho } \\
(\mathrm{g})\end{array}$ & $\begin{array}{c}\text { Sementes } \\
(\%)\end{array}$ & $\begin{array}{c}\text { Fibras } \\
(\%)\end{array}$ \\
\hline T1 & 136 & 8 & 7 & 59 & 41 \\
T2 & 146 & 4 & 3 & 55 & 45 \\
T3 & 137 & 6 & 6 & 61 & 39 \\
T4 & 145 & 6 & 5 & 52 & 38 \\
T5 & 145 & 4 & 3 & 52 & 48 \\
\hline
\end{tabular}

(1)T1: soja-milheto-soja-milheto-algodoeiro; T2: soja-amaranto-soja-nabo forrageiro-algodoeiro; T3: soja-sorgo granífero-soja-sorgo graníferoalgodoeiro; T4: soja-aveia preta-soja-aveia preta-algodoeiro; T5: soja-soja-algodoeiro. 
lha em reduzir a germinação em até $70 \%$ das plantas daninhas (Kumar, citado por Pereira, 1990). Almeida \& Rodrigues (1984) verificaram existência de efeitos alelopáticos (estímulo, retardamento ou inibição da germinação de sementes) de diversas coberturas mortas sobre diferentes plantas daninhas, em experimentos conduzidos em vaso. Em condições de campo, entretanto, tais efeitos dificilmente são comprovados, em virtude da grande diluição das substâncias alelopáticas no solo e de sua rápida decomposição pelos microrganismos (Santos \& Reis, 2001).
A aveia preta (T4) controlou algumas plantas daninhas (papuã, picão-preto e poaia) de maior incidência entre os tratamentos (Tabela 4). Segundo Roman \& Velloso (1993), a aveia preta atinge controle de $100 \%$ de papuã (Brachiaria plantaginea Link) e picão-preto (Bidens pilosa L.) e proporciona excelente controle de poaia-branca (Richardia brasiliensis Gomes).

Ao se considerar a quantidade da parte aérea das plantas de cobertura depositada em cada área (Tabela 3), observa-se que não houve diferença significativa no teor de matéria orgânica do solo (Tabela 5), prova-

Tabela 3. Produção (t/ha) da parte aérea da soja, das plantas de cobertura (milheto, amaranto, nabo forrageiro, sorgo, aveia preta) e do algodoeiro herbáceo, cultivar BRS Antares, em plantio direto no Cerrado ${ }^{(1)}$.

\begin{tabular}{cccccc}
\hline Tratamento $^{(2)}$ & Soja & Plantas de cobertura & Soja & Plantas de cobertura & Algodão \\
& $1998 / 1999$ & 1999 & $1999 / 2000$ & 2000 & $2000 / 2001$ \\
\hline T1 & $6,8 \mathrm{a}$ & $5,0 \mathrm{a}$ & $4,7 \mathrm{a}$ & $6,0 \mathrm{a}$ & $1,8 \mathrm{a}$ \\
T2 & $6,6 \mathrm{a}$ & $0,0 \mathrm{~b}$ & $5,0 \mathrm{a}$ & $2,2 \mathrm{c}$ & $1,9 \mathrm{a}$ \\
T3 & $7,3 \mathrm{a}$ & $4,0 \mathrm{a}$ & $5,3 \mathrm{a}$ & $4,5 \mathrm{ab}$ & $1,9 \mathrm{a}$ \\
T4 & $6,8 \mathrm{a}$ & $4,4 \mathrm{a}$ & $5,1 \mathrm{a}$ & $4,0 \mathrm{ab}$ & $2,0 \mathrm{a}$ \\
T5 & $6,9 \mathrm{a}$ & $0,0 \mathrm{~b}$ & $5,3 \mathrm{a}$ & $0,0 \mathrm{~d}$ & $1,8 \mathrm{a}$ \\
\hline CV $(\%)$ & 11,05 & 22,45 & 13,70 & 26,62 & 12,02 \\
F & $0,42^{*}$ & $37,36^{* *}$ & $0,30^{*}$ & $4,86^{*}$ & $0,40^{*}$ \\
\hline
\end{tabular}

${ }^{(1)}$ Médias com a mesma letra na coluna não diferem entre si a 5\% de probabilidade, pelo teste de Tukey. (2)T1: soja-milheto-soja-milheto-algodoeiro; T2: soja-amaranto-soja-nabo forrageiro-soja-algodoeiro; T3: soja-sorgo granífero-soja-sorgo granífero-algodoeiro; T4: soja-aveia preta-soja-aveia preta-algodoeiro; T5: soja-soja-algodoeiro.

Tabela 4. Levantamento de plantas daninhas (número de plantas) 90 dias após o plantio direto do algodoeiro herbáceo, cultivar BRS Antares, nas áreas sob rotação de soja com plantas de cobertura (milheto, sorgo granífero, aveia preta e nabo forrageiro) no Cerrado.

\begin{tabular}{|c|c|c|c|c|c|}
\hline \multirow[t]{2}{*}{ Planta daninha } & \multicolumn{5}{|c|}{ Tratamento $^{(1)}$} \\
\hline & $\mathrm{T} 1$ & $\mathrm{~T} 2$ & T3 & $\mathrm{T} 4$ & T 5 \\
\hline Apaga-fogo (Alternanthera tenella Colla) & & & & 6 & \\
\hline Braquiária (Brachiaria decumbens Stapf) & & 15 & & & 10 \\
\hline Capim-colchão (Digitaria horizontalis Willd.) & 10 & 8 & & & 8 \\
\hline Caruru (Amaranthus deflexus L.) & & 1 & & 2 & 1 \\
\hline Carrapicho-de-carneiro (Acanthospermum hispidum DC.) & & & & & 4 \\
\hline Corda-de-viola (Ipomoea grandifolia) & & 8 & & 2 & 8 \\
\hline Erva-quente (Spermacoce latifolia Aubl.) & & & 1 & 1 & \\
\hline Erva-de-santa-luzia (Chamaesyce hirta L. Millsp.) & 3 & & & & \\
\hline Joá (Solanum sisymbrifolium Lam.) & 1 & & & 9 & \\
\hline Leiteira (Euphorbia heterophylla L.) & 3 & 5 & 5 & 9 & 10 \\
\hline Maria-pretinha (Solanum americanum Mill) & & & & 1 & \\
\hline Mastruço (Coronopus didymus L. Sm.) & & & & 4 & 7 \\
\hline Papuã (Brachiaria plantaginea) & 2 & 14 & 3 & & 10 \\
\hline Pé-de-galinha (Eleusine indica $\mathrm{L}$. Gaerton) & 1 & 5 & 8 & 2 & 15 \\
\hline Picão-preto (Bidens pilosa L.) & 5 & 9 & 9 & & 20 \\
\hline Poaia (Richardia brasiliensis Gomes) & 2 & 22 & 6 & & 2 \\
\hline Timbete (Cenchrus echinatus L.) & 1 & & & 1 & 1 \\
\hline Trapueraba (Commelina benghalensis L.) & 2 & 6 & 5 & 3 & 4 \\
\hline Total & 30 & 93 & 37 & 40 & 92 \\
\hline
\end{tabular}

${ }^{(1)}$ T1: soja-milheto-soja-milheto-algodoeiro; T2: soja-amaranto-soja-nabo forrageiro-soja-algodoeiro; T3: soja-sorgo granífero-soja-sorgo graníferoalgodoeiro; T4: soja-aveia preta-soja-aveia preta-algodoeiro; T5: soja-soja-algodoeiro. 
Tabela 5. Análise do solo (camada de 0-20 cm) das áreas antes do plantio direto do algodoeiro herbáceo, cultivar BRS Antares no ano agrícola 2001/2002, no Cerrado $^{(1)}$.

\begin{tabular}{|c|c|c|c|c|c|c|c|c|}
\hline Tratamento $^{(2)}$ & $\begin{array}{c}\mathrm{pH} \\
\text { (água) }\end{array}$ & $\begin{array}{c}\mathrm{P} \\
\left(\mathrm{mg} / \mathrm{cm}^{3}\right)\end{array}$ & A1 & $\begin{array}{l}\mathrm{K} \\
--(\mathrm{meq} / 100\end{array}$ & $\begin{array}{l}\mathrm{Ca}+\mathrm{Mg} \\
\mathrm{g})\end{array}$ & $\mathrm{H}+\mathrm{Al}$ & $\begin{array}{l}\mathrm{V} \\
(\%)\end{array}$ & $\begin{array}{c}\text { M O } \\
(\mathrm{g} / \mathrm{kg})\end{array}$ \\
\hline $\mathrm{T} 1$ & 5,5 & $5,4 \mathrm{a}$ & $0,03 \mathrm{a}$ & $0,15 \mathrm{a}$ & $1,78 \mathrm{a}$ & $4,18 \mathrm{a}$ & $32 \mathrm{a}$ & $22 \mathrm{a}$ \\
\hline $\mathrm{T} 2$ & 5,5 & $5,0 \mathrm{a}$ & $0,02 \mathrm{a}$ & $0,16 a$ & $1,77 \mathrm{a}$ & $4,00 \mathrm{a}$ & $32 \mathrm{a}$ & $21 \mathrm{a}$ \\
\hline $\mathrm{T} 3$ & 5,6 & $5,3 a$ & $0,03 \mathrm{a}$ & $0,18 \mathrm{a}$ & $1,80 \mathrm{a}$ & $4,16 \mathrm{a}$ & $32 \mathrm{a}$ & $23 a$ \\
\hline $\mathrm{T} 4$ & 5,5 & $5,2 \mathrm{a}$ & $0,02 \mathrm{a}$ & $0,15 \mathrm{a}$ & $1,73 \mathrm{a}$ & $4,10 \mathrm{a}$ & $31 \mathrm{a}$ & $22 \mathrm{a}$ \\
\hline T5 & 5,5 & $5,2 \mathrm{a}$ & $0,02 \mathrm{a}$ & $0,13 \mathrm{a}$ & $1,98 \mathrm{a}$ & $3,87 \mathrm{a}$ & $35 \mathrm{a}$ & $22 \mathrm{a}$ \\
\hline $\mathrm{CV}(\%)$ & 2,87 & 6,91 & 146,19 & 21,13 & 17,36 & 14,55 & 18,72 & \\
\hline F & $0,56^{*}$ & $0,89 *$ & $0,29 *$ & $0,76^{*}$ & $0,32^{*}$ & $0,31 *$ & $0,49 *$ & \\
\hline
\end{tabular}

${ }^{(1)}$ Médias com a mesma letra na coluna não diferem entre si a $5 \%$ de probabilidade, pelo teste de Tukey. ${ }^{(2)}$ T1: soja-milheto-soja-milhetoalgodoeiro; T2: soja-amaranto-soja-nabo forrageiro-algodoeiro; T3: soja-sorgo granífero-soja-sorgo granífero-algodoeiro; T4: soja-aveia pretasoja-aveia preta-algodoeiro; T5: soja-soja-algodoeiro.

velmente, pelo pequeno espaço de tempo para a decomposição dos materiais depositados e por causa da textura do solo (64\% de argila). Conforme Moody et al. (1961), o não revolvimento do solo leva a uma decomposição mais lenta e gradual do material orgânico, tendo como consequiência alterações físicas, químicas e biológicas no solo que irão repercutir na sua fertilidade e na produtividade das culturas. Por outro lado, conforme Derpsch (1991), a combinação das culturas com plantas de cobertura (aveia preta, milheto, sorgo) com relação $\mathrm{C}: \mathrm{N}$ superior a 25 tende à maior permanência no solo. Na Tabela 5, observa-se que o teor de Al foi baixo. Conforme Staut \& Kurihara (1998), o algodoeiro é extremamente sensível à presença de $\mathrm{Al}$ no solo. Segundo esses autores, em solo com $\mathrm{pH}$ 5,5, o algodoeiro sofre uma série de problemas nutricionais que limitam sua produtividade.

\section{Conclusões}

1. A rotação soja-milheto-soja-milheto-algodoeiro proporciona maior produtividade do algodoeiro em plantio direto no Cerrado.

2. A palhada do milheto é mais eficiente do que a do amaranto, nabo forrageiro, sorgo e aveia preta no controle de plantas daninhas, no cultivo do algodoeiro em plantio direto no Cerrado.

\section{Referências}

ALLISON, L.E. Organic carbon. In: BLACK, C.A.; EVANS, D.D.; WHITE, J.L.; ENSMINGER, L.E.; CLARK, F.E. (Ed.). Methods of soil analysis: chemical and microbiological properties. Madison: American Society of Agronomy, 1965. pt.2, p.1367-1378. (Agronomy, 9).
ALMEIDA, F.S.; RODRIGUES, B.N. Guia de herbicidas: contribuição para uso adequado em plantio direto e convencional. Londrina: Iapar, 1984. 482p.

ANDERSON, W.P. Methods of weed control. In: ANDERSON, W.P. Weed science: principles. 2nd ed. Saint Paul: West, 1983. p.65-122.

ASHLEY, D.A. C-Labelled photosynthetic translocation and utilization in cotton plants. Crop Science, v.12, p.69-74, 1972.

BELTRÃO, N.E. de M.; BEZERA, J.R.C. de M. Recomendações técnicas para o cultivo do algodoeiro herbáceo de sequeiro e irrigado nas regiões Nordeste e Norte do Brasil. Campina Grande: Embrapa-CNPA, 1993. 72p. (Circular Técnica, 17).

BELTRÃO, N.E. de M.; MELHORANÇA, A.L. Plantas daninhas: importância e controle. In: ALGODÃO: informações técnicas. Dourados: Embrapa-CPAO; Embrapa-CNPA, 1998. 267p. (Embrapa-CPAO. Circular Técnica, 7).

BERNOIT, P. The start of the growing season in Northern Nigeria. Agricultural Meteorology, v.18, p.91-99, 1977.

BOLONHEZI, A.C.; FREITAS, H.A. de S.; DELAVALE, F.G.; JUSTI, M.M.; FUZATTO, M.; CIA, E. Desempenho de variedades de algodão herbáceo - ensaio nacional: características agronômicas e retenção de estruturas reprodutivas. In: CONGRESSO BRASIlEIRO DE ALGODÃO, 2., 1999, Ribeirão Preto. Anais. Campina Grande: Embrapa-CNPA, 1999. p.548-550.

BROWN, S.M.; WTITWELL, T.; TOUCHTON, J.T.; BURMESTER, C.H. Conservation tillage systems for cotton production. Soil Science Society of America Journal, v.49, p.12561260, 1995.

DERPSCH, R. Controle da erosão no Paraná: sistemas de cobertura do solo, plantio direto e preparo convencional. Eschborn: Deutsche Gesellschaft für Technische Zusammenarbeit, 1991. 268p.

DERPSCH, R. Rotação de culturas: atualização em plantio direto. Campinas: Fundação Cargill, 1985. 343p.

FORTUNA, P.A.; LAMAS, F.M.; FERRAZ, C.T. Avaliação de linhagens e cultivares de algodoeiro em Mato Grosso do Sul. In: CONGRESSO BRASILEIRO DE ALGODÃO, 2., 1999, Ribeirão Preto. Anais. Campina Grande: Embrapa-CNPA, 1999. p.591-594. 
FREIRE, E.C.; FARIAS, F.J.C. Novas tendências e avanços do melhoramento genético do algodoeiro. In: SEMINÁRIO ESTADUAL DO ALGODÃO, 4.; ENCONTRO ALGODÃO MATO GROSSO 2000, 1., 1998, Cuiabá. Anais. Rondonópolis: Fundação MT, 1998. p.5-20.

GRID-PAPP, I.L.; CIA, E.; FUZATTO, M.G.; SILVA, M.M.; FERRAZ, C.A.M.; CARVALHO, N. de; CARVALHO, L.H.; SABINO, N.P.; KONDO, J.L.; PASSO, S.M. de G.; CHIAVEGATO, E.J.; CAMARGO, P.P. de; CAVALERJ, P.A. Manual do produtor de algodão. São Paulo: Bolsa de Mercadorias \& Futuros, 1992. $158 \mathrm{p}$.

LAGIÈRE, R. El algodón. Barcelona: Blume, 1976. 279p.

MELO FILHO, J.F.; SILVA, J.R.C. Erosão, teor de água no solo e produtividade do milho em plantio direto e preparo convencional de um podzólico vermelho-amarelo no Ceará. Revista Brasileira de Ciência do Solo, v.17, p.291-297, 1993.

MOODY, J.E.; SHEAR, G.M.; JONES JUNIOR, J.N. Growing corn without tillage. Soil Science Society of America Proceedings, v.6, p.516-517, 1961.

MURPHY, J.; RILEY, J.R. A modified single solution method for the determination of phosphate in natural waters. Analytica Chimica Acta, v.27, p.31-36, 1962.

PEREIRA, O. G. Produtividade do milho (Zea mays L.) do sorgo (Sorgum bicolor L. Moench), da aveia (Avena sativa), do milheto (Pennisetum americanum L.) e do híbrido (S. bicolor $\mathrm{x} S$. sudanense) e respectivos valores nutritivos sob a forma de silagem e verde picado. 1990. 86p. Dissertação (Mestrado) Universidade Federal de Viçosa, Viçosa.

ROMAN, E.S.; VELLOSO, J.A.R. de O. Controle cultural, coberturas mortas e alelopatia em sistemas conservacionistas. In: EMBRAPA. Centro Nacional de Pesquisa de Trigo (Passo Fundo, RS). Plantio direto no Brasil. Passo Fundo: Embrapa-CNPT; Fundacep; Fecotrigo; Fundação ABC; Aldeia Norte, 1993. p.77-84. SANTOS, H.P. dos; REIS, E.M. Rotação de culturas em plantio direto. Passo Fundo: Embrapa-CNPT, 2001. 212p.

SMART, J.R.; BRADFORD, J.M. No-tillage cotton yields and economics for south Texas. In: BELT WIDE COTTON CONFERENCES, 1998, San Diego. Proceedings. Memphis: National Cotton Council, 1998. p.624-626.

STAUT, L.A.; KURIHARA, C.H. Calagem, nutrição e adubação. In: ALGODÃO: informações técnicas. Dourados: Embrapa-CPAO; Embrapa-CNPA, 1998. 267p. (Embrapa-CPAO. Circular Técnica, 7).

STEWART, J.J.; MISRA, R.D.; PRUITT, W.O.; HAGAN, R.M. Irrigation corn and grain sorghum-with a deficient supply. Transactions of the ASAE, v.18, p.270-280, 1975.

TAKIZAWA, E.K.; GUERRA, J. Tecnologia de manejo do algodão no Cerrados. In: SEMINÁRIO ESTADUAL DO ALGODÃO, 4.; ENCONTRO ALGODÃO MATO GROSSO 2000, 1., 1998, Cuiabá. Anais. Rondonópolis: Fundação MT, 1998. p.61-66.

YAMAOKA, R. Plantio direto no Estado do Paraná. Londrina: Iapar, 1991. 241p. (Circular Técnica, 23).

Recebido em 12 de maio de 2003 e aprovado em 2 de dezembro de 2003 